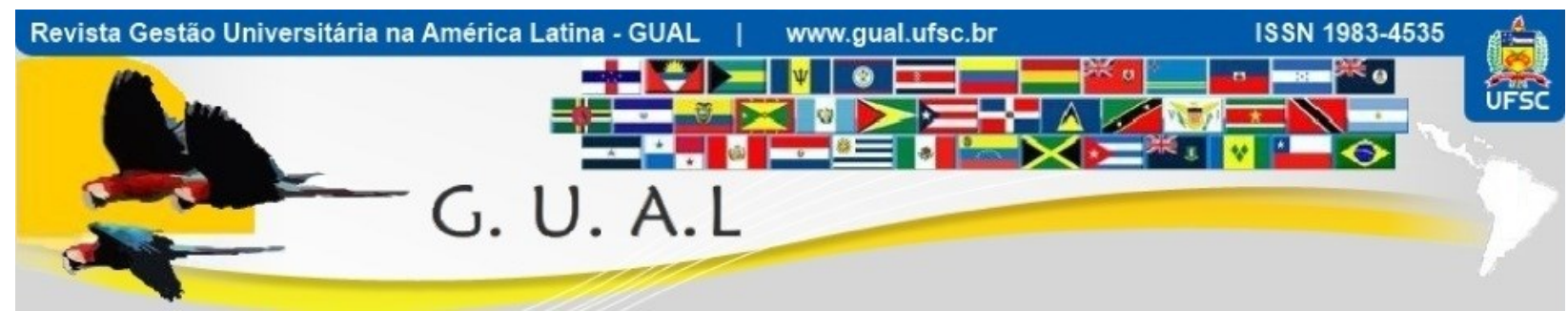

DOI: http://dx.doi.org/10.5007/1983-4535.2014v7n1p18

\title{
PERFIL METODOLÓGICO DA PRODUÇÃO CIENTÍFICA NO COLÓQUIO INTERNACIONAL SOBRE GESTÃO UNIVERSITÁRIA NAS AMÉRICAS
}

\author{
METHODOLOGY PROFILE OF THE SCIENTIFIC PRODUCTION IN THE \\ INTERNATIONAL COLLOQUIUM ON UNIVERSITY MANAGEMENT IN THE \\ AMERICAS
}

\begin{abstract}
Alair Ferreira de Freitas, Doutorando Universidade Federal de Minas Gerais - UFMG alairufv@yahoo.com.br

Danilo de Melo Costa, Doutorando Universidade Federal de Minas Gerais - UFMG danilo_mcosta@yahoo.com.br

Ivan Beck Ckagnazaroff, Doutor Universidade Federal de Minas Gerais - UFMG ivanbeck00@gmail.com

Francisco Vidal Barbosa, Doutor Universidade Federal de Minas Gerais - UFMG fvberlim@gmail.com
\end{abstract}

Recebido em 02/março/2013

Aprovado em 15/dezembro/2013

Sistema de Avaliação: Double Blind Review 


\title{
RESUMO
}

A educação superior é um dos principais pilares para as nações buscarem o desenvolvimento tecnológico e a capacitação da população. Por este motivo, torna-se cada vez mais frequente o debate em prol de uma gestão universitária eficiente. Sendo o Colóquio Internacional sobre Gestão Universitária nas Américas um dos principais eventos para a comunicação científica na área, o presente artigo objetiva identificar as abordagens metodológicas da produção científica dos eventos, traçando um perfil metodológico dos artigos. Para tanto, analisou-se 293 artigos científicos divididos em nove eventos (Colóquio I ao IX). Os dados coletados foram divididos nas seguintes categorias: Pesquisa Científica, Caracterização do estudo, Abordagem, Método de Pesquisa, Coleta de Dados e Análise de Dados. Os resultados demonstram uma evolução no rigor metodológico dos artigos com o passar dos anos, mas sinalizou a necessidade de se expandir os tipos de métodos utilizados. Finalmente, demonstrou-se que o Colóquio Internacional sobre Gestão Universitária nas Américas é um evento que atingiu um alto nível de maturidade e está pronto para receber as mais diversas contribuições metodológicas para ampliação dos estudos na importante área da gestão universitária.

Palavras-Chave: Métodos de Pesquisa. Administração Universitária. Pesquisa Científica.

\begin{abstract}
Higher education is a key pillar for nations achieve technological development and qualification of the population, therefore, it becomes increasingly frequent the debate in favor of a efficient university management. As the International Colloquium on University Management in the Americas one of the main events for scientific communication in this research area, this paper aims identify the methodological approaches of the scientific production of the events, tracing a methodological profile of the articles. To this end, we analyzed 293 scientific articles divided into nine events (Colloquium I to IX). The data were collected and divided into the following categories: Scientific Research, Characterization of the study, Approach, Research Method, Data Collection and Data Analysis. The results show an evolution in the methodological rigor of the articles over the years, but indicated the need to expand the types of methods used. Finally, it was demonstrated that the International Colloquium on University Management in the Americas is an event that has reached a high level of maturity and is ready to receive the most diverse methodological contributions to the expansion of studies in the important area of university management.
\end{abstract}

Keywords: Research Methods. University Administration. Scientific Research. 


\section{INTRODUÇÃO}

Desde o seu surgimento, a educação superior passou a figurar como um dos principais caminhos utilizados pela sociedade para se alcançar ascensão social e desenvolvimento tecnológico. Tal importância fez com que vários países investissem maciçamente no $3^{\circ}$ grau, alguns recebendo inclusive destaque perante suas políticas de acesso e permanência.

Embora os investimentos na educação superior não se restrinjam a alguma faixa etária, o foco dos governos sempre foi o de ampliar o indicador de jovens entre 18 a 24 anos, por esta ser considerada a idade adequada para os estudantes estarem matriculados no $3^{\circ}$ grau. Tendo como referência este indicador e o ano de 2004 (mesmo considerando que nos últimos 8 anos muito se investiu na educação superior nos países que serão citados), pode-se observar que na Argentina, o porcentual de jovens entre 18 e 24 anos matriculados no ensino superior estava próximo de $40 \%$ e também era elevado em outros países: Alemanha (50\%), França (60\%), EUA (80\%) e Canadá (quase 90\%), segundo pesquisas de Graciano e Haddad (2004). No Brasil, o índice ainda está em 17\% (INEP, 2011), mas em trajetória ascendente nos últimos anos.

Toda esta preocupação e a ampliação dos investimentos (públicos e privados) na educação superior e nas universidades fazem com que haja a necessidade de uma gestão universitária eficiente, para que as instituições de ensino superior (universidades, centros universitários, faculdades, centros de ensino superior, dentre outros) possam fornecer o retorno esperado para a sociedade. Entretanto, a gestão universitária não é um processo simples, tendo em vista que as universidades não são como as demais organizações burocráticas. Elas são organizações complexas devido a uma série de peculiaridades específicas do setor (BALDRIDGE; DEAL, 1983). Por este motivo, se faz necessária a reunião de pesquisadores e gestores da área para troca de experiências, com o objetivo de apresentar maneiras de se gerir universidades que possam ser aplicadas a vários cenários e desafios.

A necessidade por esta comunicação científica fez com que, no ano de 2000, acontecesse na cidade de Florianópolis, Santa Catarina, o I Colóquio Internacional sobre Gestão Universitária na América do Sul, por meio de uma parceria entre a Universidade Federal de Santa Catarina e a Universidade Nacional de Mar del Plata (INPEAU, 2012a). Da referida oportunidade até o ano de 2013, já aconteceram 13 eventos, sendo o $12^{\circ}$ na cidade de 
Veracruz, no México, o que fez com que o evento, por questões de abrangência, alterasse seu nome para Colóquio Internacional sobre Gestão Universitária nas Américas.

A importância dos eventos científicos centra-se na possibilidade de comunicação entre diferentes pesquisadores, pertencentes às mais diversas instituições de ensino. Tais comunicações se apresentam em forma de artigos científicos, formato institucionalizado em todo o mundo como mecanismo principal de divulgação de pesquisas científicas. Como tal, as pesquisas se amparam sobre métodos científicos para investigar com rigor os problemas da gestão. Os métodos, técnicas e instrumentos de pesquisa utilizados nas comunicações científicas condicionam o olhar emitido sobre a gestão universitária.

Tendo em vista que o Colóquio Internacional sobre Gestão Universitária nas Américas trata de um tema estratégico para as sociedades e que já atingiu indicadores importantes, como a marca de mais de 2.000 artigos apresentados em suas edições, seria relevante analisar o padrão metodológico destes trabalhos, tendo por pressupostos que a pesquisa pode auxiliar no desenvolvimento da gestão do ensino superior e que a metodologia é um dos principais condicionantes da eficácia das pesquisas. O objetivo do presente artigo é identificar e descrever as abordagens metodológicas dos artigos dos eventos, traçando um perfil metodológico da produção científica. Foram analisados os Colóquios I ao IX, pois são os que possuem a base de artigos disponível na Internet.

Finalmente, a referida análise poderá servir de referência para se compreender quais são os métodos mais utilizados, quais métodos representam oportunidades de pesquisa, quais métodos poderiam ser incorporados aos estudos desta área, bem como etapas do processo metodológico que poderiam ser mais bem descritas nos respectivos estudos analisados. Isso pode contribuir para que pesquisadores da área reflitam sobre a importância do rigor metodológico e a variedade de opções metodológicas encontradas nas ciências humanas e sociais.

\section{GESTÃO UNIVERSITÁRIA E SUAS PECULIARIDADES}

Para melhor compreensão da gestão universitária e de seus aspectos e peculiaridades, a presente seção apresenta a importância de se pensar na gestão das universidades de maneira eficiente. A sessão é concluída apresentando um breve histórico do Colóquio Internacional sobre Gestão Universitária nas Américas. 


\subsection{NECESSIDADE DE UMA GESTÃO UNIVERSITÁRIA}

Loureiro (1986) e Fava-de-Moraes (2000) ressaltam a importância das universidades para a formação de pessoas qualificadas, o que faz com que haja grande auxílio no desenvolvimento socioeconômico de qualquer país. A universidade, enquanto instituição central na produção da ciência, pode determinar a estrutura e o modo de funcionamento de uma sociedade. Chaui (2003) defende que uma das características da universidade é a pluralidade de visões científicas e políticas, sendo este um contexto de conflitos que influi na gestão universitária.

Tendo como referência uma definição normativa, o Artigo $52^{\circ}$ da Lei de Diretrizes e Bases da Educação Nacional, define as universidades como "[...] instituições pluridisciplinares de formação dos quadros profissionais de nível superior, de pesquisa, de extensão e de domínio e cultivo do saber humano". Esta definição ressalta o papel social das instituições universitárias, sendo o centro de formação e difusão de conhecimentos. Complementando essa definição, a mesma lei ainda caracteriza as universidades por meio da: "produção intelectual institucionalizada mediante o estudo sistemático dos temas e problemas mais relevantes, tanto do ponto de vista científico e cultural, quanto regional e nacional" (BRASIL, 1996, p. 16).

Após a segunda-guerra, houve um grande crescimento da demanda pelo ensino superior em todos os países do mundo. A partir de então o tema "gestão universitária" passou a se tornar recorrente em várias pesquisas e comunicações científicas, isto porque as universidades passaram ao longo do pós-guerra a serem geridas sob uma perspectiva mais profissional, utilizando ferramentas da administração (LOBO; SILVA FILHO, 1998).

Para Lobo e Silva Filho (1988), esta preocupação com a gestão se dá principalmente pelo custo que as universidades representam às nações. Caso os resultados não sejam um acesso democratizado, uma formação variada de profissionais qualificados e um retorno com pesquisas que irão ajudar o desenvolvimento de uma nação a universidade acaba por representar mais prejuízos do que lucros, desta forma, uma gestão eficiente em busca destes objetivos se faz necessária e fundamental.

Os gestores das universidades deveriam trabalhar em prol de uma formação efetiva e eficiente da sociedade, para geração de mão de obra qualificada, que ira trabalhar para o desenvolvimento da nação, sendo este o papel primordial das universidades (LOUREIRO, 1986; CHAUI, 2003). A partir do momento que se busca uma gestão universitária que pode 
cumprir com estes desafios, os resultados irão impactar positivamente todo o desenvolvimento da nação e principalmente do contexto regional ao qual as universidades estão inseridas.

A questão das políticas públicas também deve ser muito bem avaliada sobre o âmbito de uma gestão universitária. Bryner (2010) afirma que o governo é o responsável por criar as políticas públicas, entretanto, na maioria dos casos, não são os mesmos criadores das políticas os responsáveis por sua implementação. O que normalmente acontece é a aplicação das políticas publicas desenvolvidas pelo governo realizadas pelas organizações públicas que serão afetadas por tais políticas. Se os respectivos gestores das universidades não forem capazes de realizar a gestão das políticas, todo o processo poderá ficar comprometido.

Tendo em vista este contexto e a complexidade da gestão universitária, se faz necessária a criação de oportunidades de comunicação científica para que pesquisadores de várias universidades do Brasil e do mundo possam compartilhar suas percepções a respeito da melhor maneira de se gerir as universidades, ou de práticas já consolidadas que poderiam ser aplicadas a outros cenários. O Colóquio Internacional sobre Gestão Universitária nas Américas erigiu como um espaço institucional essencial para oportunizar o diálogo científico e incentivar a ampliação das pesquisas sobre o tema (INPEAU, 2012b).

\subsection{COLÓQUIO INTERNACIONAL SOBRE GESTÃO UNIVERSITÁRIA NAS AMÉRICAS}

Em 1988 surge na Universidade Federal de Santa Catarina o Núcleo de Estudos e Pesquisas em Administração Universitária (NUPEAU), que posteriormente se torna o Instituto de Pesquisa e Estudos em Administração Universitária (INPEAU), com a perspectiva de ampliar a geração de conhecimentos sobre o tema da Gestão Universitária por meio de pesquisas. O INPEAU tem como objetivo: “(...) gerar, disseminar e preservar o conhecimento científico e tecnológico desenvolvido na área de Administração Universitária, visando a construção de um moderno sistema de educação superior" (INPEAU, 2011).

O Colóquio Internacional sobre Gestão Universitária nas Américas (anteriormente Colóquio Internacional sobre Gestão Universitária na América do Sul) surge como uma necessidade de se ampliar a comunicação científica dos estudiosos da área. O I Colóquio Internacional sobre Gestão Universitária na América do Sul foi criado no ano 2000, mediante a uma parceria entre as universidades: Universidade Federal de Santa Catarina (Brasil) e a Universidade Nacional de Mar del Plata (Argentina). O evento aconteceu na cidade de 
Florianópolis, Santa Catarina, Brasil. Na referida oportunidade, coube ao INPEAU coordenar o evento. "A presença de autoridades acadêmicas de países como a Colômbia, Venezuela, Paraguai, Argentina e Uruguai e de praticamente todas as regiões brasileiras, foi uma demonstração do sucesso e da importância do Colóquio.” (INPEAU, 2012a).

Devido aos resultados do primeiro evento, os Colóquios II e III aconteceram nas cidades de Mar del Plata e Buenos Aires, respectivamente. Além das instituições já participantes, o II Colóquio ainda contou com a parceria da Universidade Nacional da Patagônia "San Juan Bosco" (Argentina) e o III Colóquio com a participação da Universidade Nacional de Tres de Febrero (Argentina) (INPEAU, 2012c; INPEAU, 2012d). No ano de 2004 o IV Colóquio retorna a cidade de Florianópolis. Posteriormente, no ano de 2005, acontece o V Colóquio na Cidade de Mar del Plata, com destaque para os 249 artigos aprovados para apresentação no respectivo evento. O VI Colóquio aconteceu na cidade de Blumenau (Brasil) em 2006, na Universidade Regional de Blumenau (FURB) e contou com a parceria da Universidade Federal de Santa Catarina (UFSC) também do Brasil além das universidades Argentinas: Universidade Nacional de Mar del Plata (UNMdP), Universidade Nacional Três de Febrero (UNTREF), além da universidade Uruguaia: Universidade de la Empresa (UDE) (INPEAU, 2012e).

O VII Colóquio, seguindo uma sequência de Brasil / Argentina, acontece em Mar del Plata. Entretanto, como fruto da inclusão de uma parceria com a Universidade Tecnológica Intercontinental (UTIC), o evento acontece na cidade de Assunção, no Paraguai, se expandindo para outras regiões da América do Sul. Os próximos eventos (IX, X e XI) aconteceram nas cidades de Florianópolis, Mar del Plata e novamente em Florianópolis. O volume de artigos aprovados e apresentados nestes eventos cresceu substancialmente a cada ano (INPEAU, 2012e).

No ano de 2012 acontece o XII Colóquio, que precisa ter seu nome ampliado, retirando a delimitação "na América do Sul” e inserindo a delimitação "nas Américas”, uma vez que o evento rompe as amarras sul-americanas e acontece na cidade de Veracruz, no México. O XII Colóquio foi uma realização conjunta das Universidades: Universidade Veracruzana, do México, Universidade Federal de Santa Catarina (UFSC) e Universidade Federal da Fronteira Sul (UFFS), do Brasil, Universidade Nacional de Mar del Plata (UNMdP) e Universidade Nacional de Tres de Febrero (UNTREF), da Argentina, alem da Universidade Tecnológica Intercontinental (UTIC) e a Universidade Nacional de Caaguazú 
(UCA), do Paraguai (INPEAU, 2012e). O XIII Colóquio, realizado em 2013, retorna para a cidade de Buenos Aires, definindo como tema central o desempenho acadêmico e a eficácia social das universidades e recebe a contribuição de mais de 300 trabalhos, se consolidando como um dos principais eventos do mundo no que se refere à Gestão Universitária.

\section{MÉTODOS E TÉCNICAS EM PESQUISA CIENTÍFICA}

De acordo com Gil (1999), para que um conhecimento possa ser considerado como científico é preciso identificar as operações mentais e técnicas que operacionalizam tal verificação, ou seja, o método que mediou a produção do conhecimento. $\mathrm{O}$ autor define método como caminho para se alcançar determinado fim e método científico como o conjunto de procedimentos técnicos e intelectuais adotados para se atingir o conhecimento. Para Lakatos e Marconi (1991), não há ciência sem o emprego de método científico.

O método sempre esteve em pauta na comunidade científica. Muito já foi proposto acerca de métodos universais para produção do conhecimento, como foram alguns ligados às ciências naturais. Se o método pode ser considerado o caminho para um certo conhecimento, é preciso (e preferível) pensar na diversidade de métodos, guiados pelos objetivos das pesquisas (os mais diversos) e o tipo de conhecimento a se alcançar, que varia de acordo com o campo temático das ciências.

O processo formal e sistemático de aplicação e desenvolvimento dos métodos científicos é definido por Gil (1999) como pesquisa, cujo objetivo principal é descobrir respostas para problemas mediante o emprego de procedimentos científicos. $\mathrm{O}$ autor sugere uma tipologia das pesquisas quanto a sua caracterização, indicando como modelos mais gerais as pesquisa exploratórias, descritivas e explicativas. As pesquisas exploratórias são as que apresentam menor rigidez no planejamento e tem como finalidade desenvolver, esclarecer e modificar conceitos e ideias, considerando problemas mais precisos ou a formulação de hipóteses pesquisáveis para estudos posteriores. A pesquisa descritiva utiliza de técnicas padronizadas de coleta de dados, pois procura descrever as características de determinada população ou fenômeno, ou as relações entre elas. O tipo mais complexo de pesquisa é a explicativa, pois busca identificar os fatores que determinam ou contribuem para a ocorrência do fenômeno, ou seja, aprofundar o conhecimento da realidade e da razão dos acontecimentos (GIL, 1999). 
As pesquisas também são tipificadas quanto a sua abordagem, como quantitativas e qualitativas, havendo também pesquisas que utilizam das duas abordagens, explorando suas potencialidades no modelo que caracteriza-se como quali-quanti. A definição da pesquisa como qualitativa ou quantitativa é também uma opção acerca de seus pressupostos filosóficos sobre a natureza do mundo e sobre que tipo de dados deverão ser coletados (HUFF, 2008). De acordo com Lyons e Doueck (2010), na pesquisa qualitativa as informações obtidas não podem ser quantificáveis e a interpretação dos fenômenos e a atribuição de significados são básicas no processo de pesquisa qualitativa. Para Creswell (2009) a pesquisa qualitativa é importante quando o contexto de investigação não é suficientemente compreendido e quando as perspectivas dos sujeitos de pesquisa são cruciais. Além disso, a pesquisa qualitativa é ainda caracterizada por ocorrer no cenário natural do problema de pesquisa e é emergente ao invés de estritamente pré-configurada. Já a pesquisa quantitativa, para Lyons e Doueck (2010) traduz em números as opiniões e informações para serem classificadas e analisadas, ou seja, pretende traduzir uma realidade através da mensuração de variáveis que lhe são constitutivas, utilizando técnicas estatísticas.

Em relação aos métodos de pesquisa, encontram-se uma infinidade de possibilidades, alguns mais afins a abordagens qualitativas e outros às quantitativas. O estudo de caso é um método muito difundido, principalmente em pesquisas qualitativas. Ele é caracterizado por estudo profundo e exaustivo de um ou de poucos objetos, de maneira a permitir o seu conhecimento amplo e detalhado. Para Yin (2005), o estudo de caso analisa um fenômeno dentro de um contexto específico, quando as fronteiras entre o fenômeno e este contexto não estão muito bem definidas.

A pesquisa Survey é outro método bastante popular, mas em pesquisas quantitativas. Ela pode ser descrita como a obtenção de dados ou informações sobre características, ações e opiniões de determinado grupo de pessoas, indicado como representante de uma populaçãoalvo, por meio de um instrumento de pesquisa, geralmente um questionário, buscando descrições quantitativas e usando instrumentos pré-definidos (FREITAS, et al., 2000). Malhotra (2001) ressalta que survey é um questionário dado a uma amostra de uma população e destinado a provocar informações específicas dos entrevistados, sendo que o questionário é geralmente estruturado visando a uma certa padronização do processo de coleta de dados.

Outro método de pesquisa é a pesquisa-ação, que de acordo com Vergara (2005) visa à resolução de problemas por meio de ações definidas por pesquisadores e sujeitos envolvidos 
com a situação sob investigação. Objetiva, simultaneamente, a intervenção, a elaboração e o desenvolvimento de teoria. Outro exemplo de método é a etnografia, que foi historicamente apropriada como uma antropologia descritiva dos modos de vida da humanidade, e introduzida como um modo de descrição social científica de uma pessoa ou da configuração social de uma população, visando descrever interações sociais, crenças, práticas e artefatos, revelar comportamentos e interpretar significados (CHIZZOTI, 2006). Já o método da história de vida constitui-se num relato retrospectivo, oral ou escrito, da experiência pessoal de um indivíduo, reconstituindo fatos que foram significativos e constitutivos de sua vida (CHIZZOTI, 2006).

A análise de discurso e a análise de conteúdo também têm sido consideradas por alguns autores como métodos de pesquisa. Entretanto, são também descritas como técnicas de análise de dados, destacando que aí residiriam suas principais contribuições. Considerando que nos artigos analisados não houve menção a elas como métodos, mas sim como técnicas, elas foram assim classificadas para os fins deste artigo. Para Bardin (2011), a análise de conteúdo pode ser caracterizada como um conjunto de técnicas de análise das comunicações que utiliza procedimentos sistemáticos e objetivos de descrição do conteúdo empírico que permitam inferências sobre as condições de produção de significados e sentidos exteriorizados no discurso. Chizzotti (2006) complementa argumentando que análise de conteúdo consiste em relacionar a frequência da citação de alguns temas, palavras ou ideias em um texto para medir o peso relativo atribuído a um determinado assunto pelo seu autor. Já a análise de discurso não se restringe à estrutura ordenada de palavras ou a uma descrição das comunicações, buscando desvelar também aquilo que está implícito nos discursos e os elementos que o subjazem, como as relações de poder, conflitos, ideologias, etc., mediadas pela linguagem (CHIZZOTI, 2006). Portanto, a análise do discurso não se preocupa em analisar a frequência de temas, mas como ele está disposto e é refletido e refratado no discurso, indo além do discurso explícito, analisando também seu o contexto em que ele foi produzido. Associado a essas técnicas também como uma técnica de análise de dados, mas em abordagens quantitativas, está a estatística descritiva, que procura organizar, descrever e sumarizar um conjunto de dados quantitativos por meio de técnicas estatísticas (MANN, 1995).

Como instrumentos de coleta de dados, um dos mais comuns e difundidos são as entrevistas, que podem ser abertas, sem perguntas pré-estabelecidas, mas apenas um ponto de 
partida para desencadear o diálogo, as semi-estruturadas, que definem um conjunto moderado de questões orientadoras, mas não se prendem apenas a elas, e as estruturadas, que são realizadas com base em um conjunto bem definido de perguntas. Os questionários também compõem o conjunto dos instrumentos de coleta mais populares e são fundamentais em pesquisas quantitativas. Tais instrumentos se restringem à coleta de dados individualmente. Mas existem também instrumentos de coleta de dados em grupo, como o chamado grupo de foco. O grupo de foco (Focus group) é um tipo de entrevista em profundidade realizada em grupo, cujas reuniões têm características definidas quanto à proposta, ao tamanho, à composição e aos procedimentos de condução. $\mathrm{O}$ foco ou o objeto de análise é a interação dentro do grupo (GODOI, BANDEIRA-DE-MELO e SILVA, 2006). A observação é outro consistente instrumento de coleta de dados, por meio do qual o pesquisador se insere na realidade cotidiana de seu objeto de pesquisa para observar e registrar os acontecimentos, sem interferir naquela realidade.

Como instrumento de coleta, a pesquisa bibliográfica e a documental são também usuais e relevantes. A pesquisa bibliográfica é desenvolvida a partir de material já elaborado, como os livros e artigos científicos. Para Gil (1999), A pesquisa bibliográfica é muito comum em estudos exploratórios e geralmente desenvolvida a partir da técnica de análise de conteúdo. A pesquisa documental se assemelha a pesquisa bibliográfica, mas se diferencia pela natureza das fontes dos dados, pois na documental utiliza-se de materiais que não receberam tratamento analítico ou que podem ser reelaborados de acordo com os objetivos da pesquisa (GIL, 1999).

Essa discussão acerca dos métodos e técnicas de pesquisa científica, mesmo que sinóptica, já expõe a variedade de caminhos que podem ser seguidos pelos pesquisadores nas mais diversas áreas do conhecimento científico. Além disso, percebe-se a grande complexidade no planejamento e execução de pesquisa. Dar atenção a esta discussão, seja na operacionalização de pesquisas ou na elaboração de artigos científicos, pode contribuir para se pensar o rigor com que os métodos são empregados e para se buscar novos métodos e técnicas para as pesquisas.

\section{METODOLOGIA}

Neste artigo, em função de seu objetivo, o trabalho de pesquisa foi concebido como um estudo empírico - descritivo. O corpus para o estudo empírico compreendeu a observação de amostra dos trabalhos publicados no Colóquio Internacional sobre Gestão Universitária nas 
Américas. O estudo se caracteriza como descritivo por buscar por essência a enumeração e a ordenação de dados, sem o objetivo de comprovar ou refutar hipóteses exploratórias (ALYRIO, 2008). Quatro aspectos são abordados pela Pesquisa Descritiva: descrição, registro, análise e interpretação de fenômenos atuais, objetivando o seu funcionamento no presente (LAKATOS; MARCONI, 1986). O caráter descritivo do trabalho se deu por meio da análise dos artigos científicos, identificando e descrevendo suas características metodológicas.

O presente estudo tem abordagem quantitativa, na medida em que foram utilizados dados numéricos e estatísticos referentes aos artigos apresentados nos eventos. A coleta de dados se deu meio da pesquisa bibliográfica. A população estudada foi todos os artigos apresentados nos últimos eventos que estavam disponíveis na Internet, compreendendo desde o I Colóquio até o IX, não estando disponíveis os eventos X, XI e XII para consulta. Dos 1216 artigos disponíveis que compreendia a população da pesquisa, foi aplicada a seguinte equação para definição estatística da amostra:

$$
\mathrm{n}=\frac{\mathrm{N} \cdot \mathrm{Z}^{2} \cdot \mathrm{p} \cdot(1-\mathrm{p})}{\mathrm{Z}^{2} \cdot \mathrm{p} \cdot(1-\mathrm{p})+\mathrm{e}^{2} \cdot(\mathrm{N}-1)}
$$

Em que: $\mathrm{n}$ - amostra calculada; N - população; Z - variável normal padronizada associada ao nível de confiança; $\mathrm{p}$ - verdadeira probabilidade do evento; e - erro amostral

Definindo-se um erro amostral de 5\% e um nível de confiança de 95\%, chegou-se a amostra de 293 artigos. A partir de então, aplicou-se uma proporcionalidade do número de artigos que deveriam ser analisados por evento, conforme a Tabela 1 a seguir:

Tabela 1 Proporcionalidade de artigos analisados por evento

\begin{tabular}{lccc}
\hline \multicolumn{4}{c}{ Proporcionalidade de Artigos } \\
\hline Colóquio & Artigos & Proporcionalidade & Análise \\
\hline Colóquio 1 & 32 & $2,63 \%$ & 7,7 \\
Colóquio 2 & 84 & $6,91 \%$ & 20,2 \\
Colóquio 3 & 123 & $10,12 \%$ & 29,6 \\
Colóquio 4 & 170 & $13,98 \%$ & 41,0 \\
Colóquio 5 & 249 & $20,48 \%$ & 60,0 \\
Colóquio 6 & 154 & $12,66 \%$ & 37,1 \\
Colóquio 7 & 154 & $12,66 \%$ & 37,1 \\
Colóquio 8 & 70 & $5,76 \%$ & 16,9 \\
Colóquio 9 & 180 & $14,80 \%$ & 43,4 \\
\hline Total & 1216 & $100,00 \%$ & 293,0 \\
\hline
\end{tabular}

Fonte: Elaborado pelos autores

Notas: Realizou-se arredondamento do número de artigos analisados. Caso fosse $>$ x,5 o arredondamento foi para mais, caso fosse $<\mathrm{x}, 5$ o arredondamento foi para menos (Ex: 7,8 arredonda-se para 8 da mesma forma que 22,4 arredonda-se para 21, não houveram casos $=x, 5)$. 
Os artigos foram aleatoriamente coletados e registrados em planilhas eletrônicas. Houve uma separação de abas buscando-se compreender cada categoria que define o perfil metodológico das pesquisas: (a) Tipo de pesquisa científica (Teórico; Empírico); (b) Caracterização da pesquisa quanto aos objetivos (Exploratório; Descritivo; Explicativo; Não Consta); (c) Tipo de abordagem da pesquisa (Qualitativo; Quantitativo; Quali-Quanti); (d) Métodos de Pesquisa (História oral/história de Vida; Etnografia; Estudo de Caso; Pesquisaação/participante; Survey; Grounded Theory; Análise de Redes; Outros; Não consta); (e) Instrumentos de coleta de dados (Documental; Bibliográfica; Questionário; Entrevista; Observação; Grupo de Foco; Outros; Não consta); e, (f) Técnica de Análise de Dados (Análise de Conteúdo; Análise de discurso; Estatística Descritiva; Categorizações; Outras; Não consta);

Os dados coletados foram analisados utilizando-se a técnica de estatística descritiva, pois se aplicou várias técnicas para se organizar, descrever e sumariar os respectivos artigos (MANN, 1995).

A limitação do estudo se deu pelo motivo de, até a data da coleta dos dados, não estar disponível para acesso na Internet a base de artigos dos 13 (treze) Colóquios que já ocorreram, havendo necessidade de uma delimitação de análise do I ao IX. Outra limitação ocorreu pelo fato de nem todos os artigos analisados apresentarem a metodologia utilizada, ficando a cargo dos autores realizarem uma análise dedutiva mediante ao conhecimento prévio de metodologia da pesquisa.

\section{RESULTADOS DA PESQUISA}

A presente seção descreve os resultados da pesquisa a partir da análise sobre o ponto de vista metodológico dos artigos observados. Em cada subsessão são apresentados os resultados de cada uma das categorias do perfil metodológico analisadas. Elas são apresentadas separadamente com fins didáticos, mas destaca-se que na operacionalização das pesquisas são questões inter-relacionadas, onde uma opção levam à outra.

\subsection{TIPO DE PESQUISA CIENTÍFICA}

No que se refere à pesquisa científica, a análise buscou compreender dentre todos os artigos analisados, quantos são Teóricos e quantos são Empíricos, separados pelo número do evento. Observou-se que há uma grande proximidade dos resultados finais, sendo utilizada a 
pesquisa Teórica em $47 \%$ das vezes e a pesquisa Empírica em 53\% das vezes. Entretanto, percebeu-se que as pesquisas Empíricas predominaram em 5 (cinco) de 9 (nove) eventos analisados. Entretanto, pode-se observar que as pesquisas teóricas tiveram seu ápice de submissão e apresentação nos Colóquios 2 e 3, considerando um crescimento substancial das pesquisas Empíricas entre os próprios eventos 2 e 3, o que culminou em um grande destaque nos colóquios 4 e 5 para a pesquisa Empírica. Ainda que o Colóquio 6 tivesse a pesquisa Empírica como predominante, a pesquisa Teórica volta a ganhar força (em termos de proporcionalidade) neste evento. Observa-se este fenômeno nos Colóquios subsequentes (7 e 8). No Colóquio 9, as pesquisas Empíricas voltam a predominar representando a preferência por este tipo de pesquisa científica.

\subsection{CARACTERIZAÇÃO DA PESQUISA QUANTO AOS OBJETIVOS}

Nesta categoria percebe-se que ao longo da trajetória do evento as pesquisa caracterizadas como exploratórias foram predominantes, seguidas pelas pesquisas explicativas. Exceto pela discrepância do colóquio 4, onde foram detectados artigos com maiores indicações de pesquisa explicativa. Não obstante a definição arbitrária dos autores sobre essa classificação, os dados demonstram que a tal tipo de pesquisa predominando associa uma agenda ainda em estágios iniciais de amadurecimento e aprofundamento, como no caso de formação de um corpus teórico mais consistente, com hipóteses mais concretas para futuras pesquisas mais explicativas.

Em geral, como apontado por Gil (1999), a caracterização das pesquisas parece se dar em ordem progressiva, das menos complexas (exploratórias) para as mais complexas (explicativas). Essa evolução é gradativa, de modo que um campo que apresente mais pesquisas exploratórias se constitui em torno das complexidades iniciais de orientação das investigações e necessidade de ampliação das discussões. O grande número de artigos teóricos que prevalecem ao longo dos eventos contribui nesse sentido.

$\mathrm{Na}$ figura a seguir está condensada as porcentagens gerais da caracterização das pesquisas quanto aos seus objetivos. 


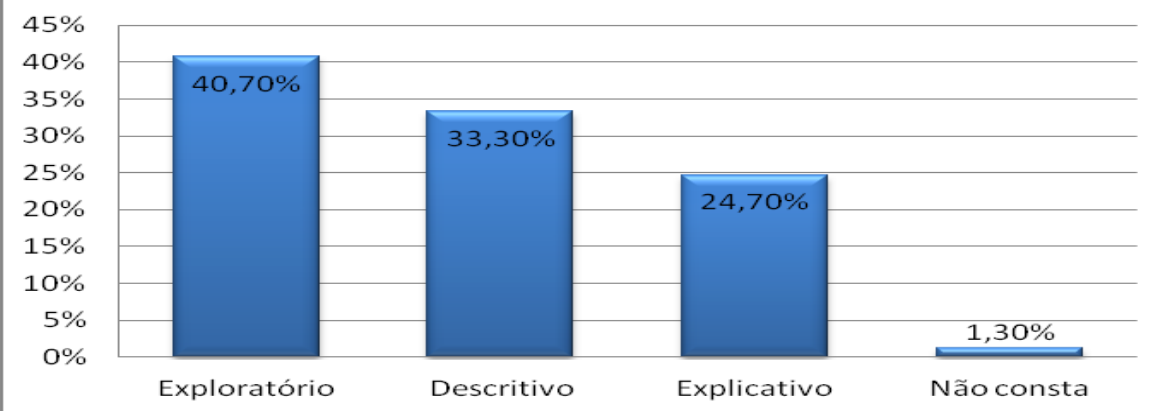

Figura 02 Caracterização dos artigos quanto aos objetivos da pesquisa nos colóquios de 1 a 9. Fonte: Dados da pesquisa (2012).

Esses dados reforçam a indicação da prevalência dos estudos exploratórios, mas deixam em evidência também que tal posição não é isolada, pois os estudos descritivos também possuem margem considerável de indicação nos artigos. Como hipótese diante desses dados, pode-se argumentar sobre uma tendência de equiparação das pesquisas exploratórias e descritivas e aumento das explicativas, caso se analise com rigor tais classificações.

\subsection{TIPOS DE ABORDAGEM DA PESQUISA}

Para se descrever a abordagem dos artigos, a análise dos dados buscou compreender se os trabalhos são qualitativos, quantitativos, ou se usam as duas abordagens, comumente conhecida como abordagem "quali-quanti". A Figura 3 apresenta a coleta no que se refere à utilização das respectivas abordagens por evento:

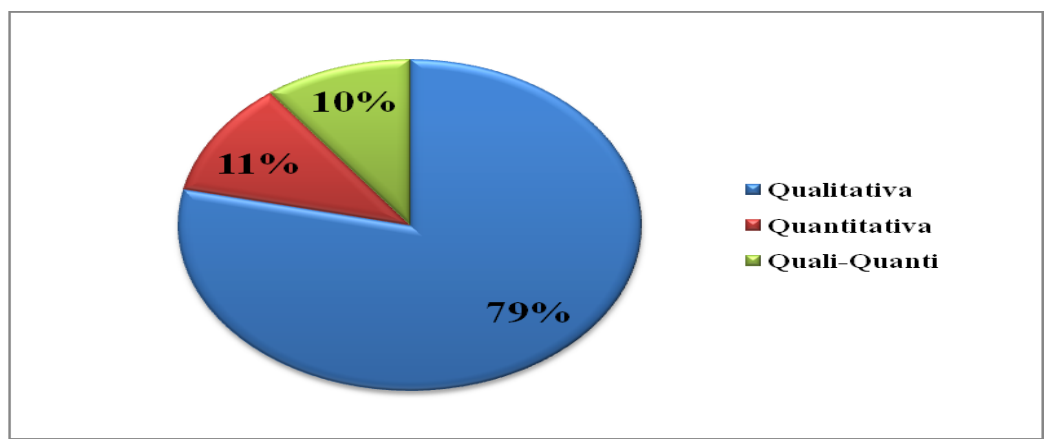

Figura 03 Tipos de abordagem da pesquisa nos artigos dos colóquios de 1 a 9. Fonte: Dados da pesquisa (2012).

De maneira geral, pôde-se observar que a maioria absoluta dos estudos utiliza apenas a abordagem Qualitativa (79\%), ficando a abordagem Quantitativa com 11\% e a abordagem Quali-Quanti por último, com 10\%. Todavia, a pesquisa revelou que a utilização de outras abordagens começa a tomar força nos últimos eventos. Os dados demonstram que entre os 
Colóquios 1 ao 5, a utilização da abordagem qualitativa foi substancialmente superior a utilização da abordagem quantitativa ou quali-quanti. Contudo, a partir do Colóquio 4, a abordagem quantitativa (e quali-quanti) começa a ganhar força, tendo seu ápice no Colóquio 6 , em que $65 \%$ dos trabalhos usaram abordagem qualitativa ante $35 \%$ dos trabalhos que utilizaram abordagens quantitativas ou quali-quanti. Os Colóquios 7 e 8 representam uma queda do uso dos métodos quantitativos mas no Colóquio 9 eles voltam a ganhar força, demonstrando que o evento começa a passar por um fenômeno de diversificação de abordagens. Mesmo assim, sugere-se uma ampliação das abordagens quantitativas e qualiquanti, haja vista que estudos com este tipo de abordagem também apresentam valiosos resultados, sobretudo quando se analisa grandes amostras.

\subsection{MÉTODOS DE PESQUISA}

Uma primeira constatação sobre estes dados, visualmente expressa na figura abaixo, é que a maioria dos artigos analisados $(58,37 \%)$ não fazia referência a um método de pesquisa. Em geral se indicavam instrumentos de coleta de dados, mas esta parecia ser a referência metodológica básica (se não a única) de muitos dos artigos. A questão de indicação do método em trabalhos científicos é de fundamental importância, não apenas para legitimá-lo enquanto contribuição ao seu campo do conhecimento, mas também para situar o leitor sobre as orientações metodológicas e a forma de condução das pesquisas, seja para maior compreensão do trabalho ou mesmo para possíveis adaptações em outras realidades.

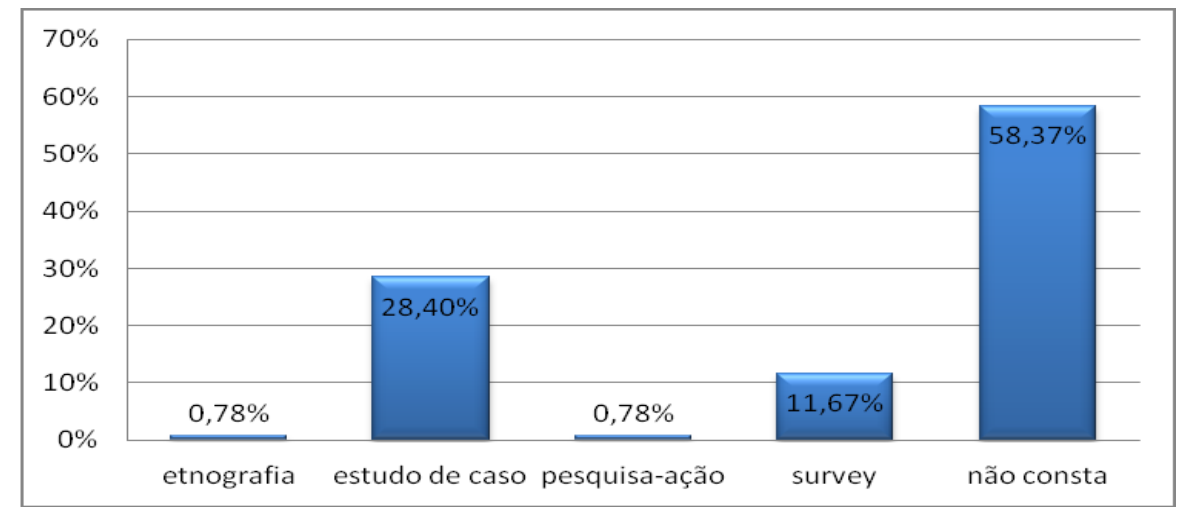

Figura 04 Métodos de pesquisa.

Fonte: Dados da pesquisa (2012).

Como método de pesquisa, o estudo de caso foi o mais citado nos trabalhos analisados, alcançando $28,40 \%$ do total. Além de sua popularidade, a grade difusão do estudo de caso como referência metodológica tem lhe dado expressão significativa em diversas áreas do 
conhecimento, mas é usado com notória frequência em pesquisas de abordagem qualitativa, que exigem maior aprofundamento no contexto pesquisado. Entretanto, sua popularidade tem causado certas críticas, pois o método acaba sendo usado sem nenhum rigor, e qualquer estudo que se proponha a analisar uma unidade específica, como uma empresa ou uma universidade, são passíveis de serem classificados como estudo de caso, ou seja, há certa generalização do uso do método e do discurso sobre ele. Esta é uma preocupação à qual se deve dar atenção, pois pode-se acabar banalizando o método e depreciando as pesquisa com seu uso inadequado.

A Survey apareceu em $11,67 \%$ dos trabalhos, apenas em pesquisas quantitativas. Esse tipo de método é historicamente muito difundido também, e é associado ao emprego de estatística descritiva. Outros métodos que aparecem, mas com menor intensidade, foram a etnografia e a pesquisa-ação, ambas com 0,78\%. Apesar do número muito baixo, a identificação destes métodos já é relevante para ser ressaltada aqui. Tais métodos são empregados em pesquisa qualitativa e possuem grande contribuição e potencial como método de pesquisa. Em geral são usados em pesquisas com um viés epistemológico mais interpretavista, pois consideram a percepção dos sujeitos da pesquisa e sua ativa interação com o pesquisador, sendo que os resultados da pesquisa são extraídos desta interação. Assim, o pesquisador não se coloca como neutro na pesquisa, pois sua subjetividade nunca é eliminada. Na etnografia, a vivência do pesquisador no cotidiano da gestão universitária, observando as interações e as rotinas diárias, pode ser um caminho interessante para se compreender as dinâmicas internas das instituições. Na pesquisa-ação, com a participação ativa dos sujeitos da pesquisa na identificação e análise de problemas da gestão universitária pode-se obter insumos importantes para a gestão dos casos estudados e seriam fundamentais na proposição de pesquisas mais interativas e alinhadas às demandas das instituições.

\subsection{TÉCNICAS DE COLETA DE DADOS}

No que dizer respeito às técnica de coleta de dados, buscou-se compreendê-las tendo como referência aquelas mais comuns para o campo de estudo contemplado no presente artigo. Desta forma, os artigos foram categorizados nas técnicas: Documental, Bibliográfica, Questionário, Entrevista, Observação, Grupo de Foco, Outros e Não Consta, conforme Figura 5. 


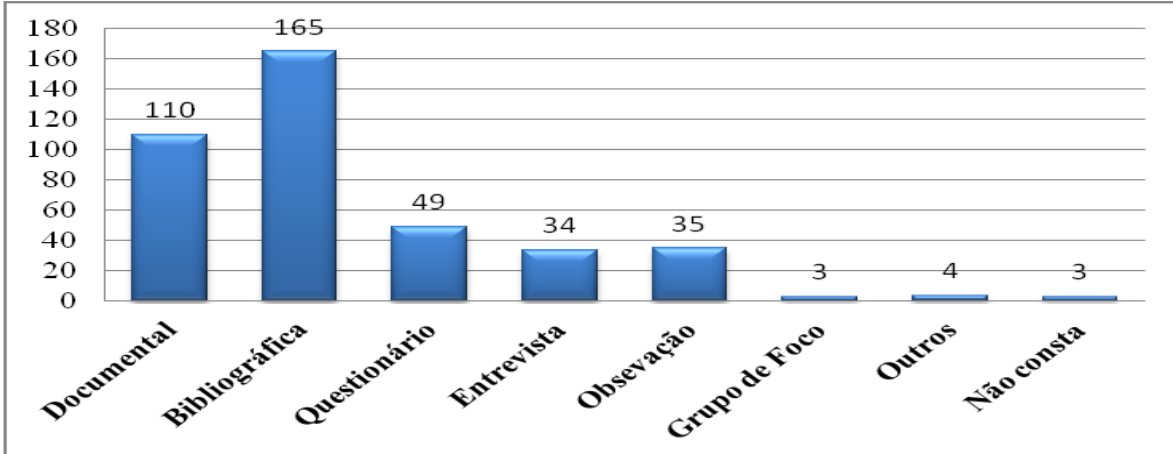

Figura 05 Instrumentos de coleta de dados.

Fonte: Dados da pesquisa (2012).

Nota: Um artigo pode aplicar mais de uma coleta de dados.

Os dados acima demonstram uma predominância das técnicas de coleta de dados Bibliográfica e Documental, entretanto, não se pode afirmar que estes métodos são unicamente os mais utilizados, uma vez que há grande combinação das técnicas de coleta de dados em vários eventos. Pôde-se perceber que há uma combinação de técnicas, e quando se abre estes dados, se observa que esta combinação esta quase sempre associada à pesquisa bibliografia ou documental (ou ambas) junto de outro método.

Ao analisar os dados desta categoria, desconsiderando o amplo destaque das técnicas Documental e Bibliográfica (pelos motivos supracitados), pode-se perceber que as técnicas questionário e entrevistas possuem resultados representativos, entretanto, tem-se diminuído a utilização do questionário e aumentado a utilização da entrevista nos últimos eventos, o que pode indicar um fenômeno a ser confirmado nos próximos eventos. A técnica de observação também foi bastante utilizada, entretanto identificou-se a necessidade de ampliação das técnicas de coleta de dados. Técnicas como os Grupos de Foco foram utilizadas em raras oportunidades.

\subsection{TÉCNICA DE ANÁLISE DE DADOS}

As técnicas de análise de dados representam os processos pelos quais os dados, sejam eles primários ou secundários, são tratados pelo pesquisador para então dotá-los de sentido segundo seus objetivos de pesquisa. Adotar uma técnica nesta etapa de elaboração do conhecimento científico está associado à manutenção do rigor metodológico, pois o percurso metodológico de uma pesquisa não se encerra com os instrumentos de coleta de dados. Até mesmo a elaboração de artigos científicos requerem procedimentos metodológicos. 
Os resultados desta pesquisa, como exposto nas figuras abaixo, mostraram que em apenas três dos nove eventos o número de artigos que mencionavam a utilização de alguma técnica de tratamento e análise de dados superou o número de artigos que não identificaram nenhuma técnica. Uma limitação decorrente disso é que os leitores podem ter dificuldades para compreender como certos autores fazem as inferências que estão propondo e, assim, de que modo sua argumentação está sendo construída com base nos dados analisados. Até mesmo em artigos teóricos, que utilizam de dados bibliográficos, poderiam expor com maiores detalhes seu percurso metodológico, demonstrando as categorias a partir das quais a pesquisa bibliográfica foi feita, de que forma os dados foram selecionados e como estes foram apropriados para a discussão empreendida.

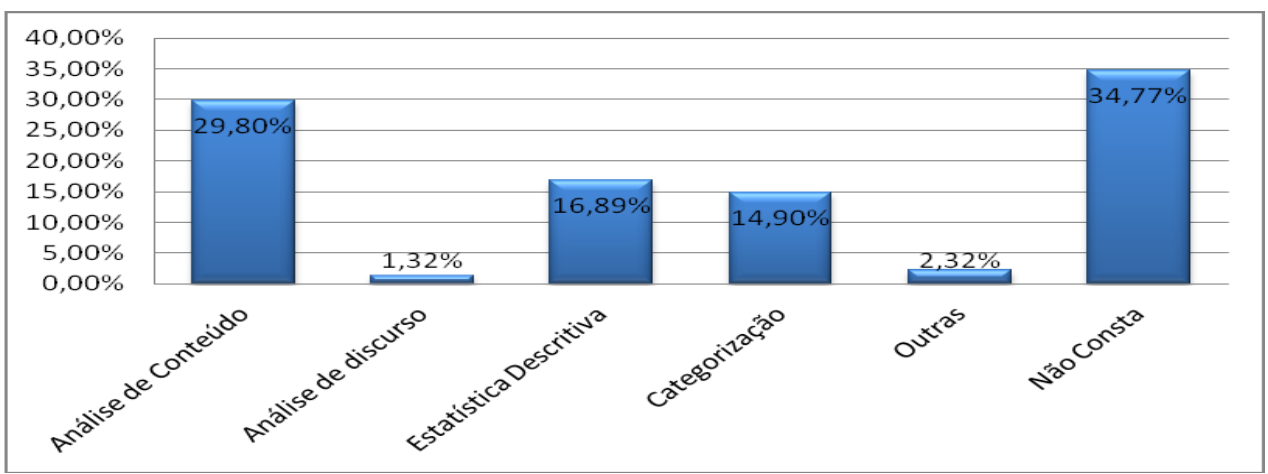

Figura 06 Técnicas de analise de dados nos colóquios de 1 a 9.

Fonte: Dados da pesquisa (2012).

Percebe-se com as análises e na demonstração da figura que, em termos gerais, ao longo dos congressos foram identificados mais artigos em que não constavam técnicas de análise de dados, numa proporção de $34,77 \%$. Isso pode se constituir como problemática em alguns trabalhos, pois a utilização e descrição de técnicas de análise de dados possibilita ao leitor descobrir o caminho percorrido pelo pesquisador no tratamento dos dados que foram coletados.

A técnica mais comum encontrada foi a análise de conteúdo, em 29,8\% dos artigos analisados. Ta técnica é bastante difundida nos trabalhos acadêmicos em ciências humanas e sociais, possuindo como principal referência a obra de Lawrence Bardin. Como mencionado anteriormente, a técnica parte da análise de um conteúdo empírico para, através de procedimentos sistemáticos de fragmentação e categorização de dados, extrair sentidos e significados que possam ser interpretados pelo pesquisador. É muito utilizado em pesquisas bibliográficas e documentais, o que pode relativamente explicar o número expressivo 
encontrado aqui, uma vez que houve quantidade significativa de artigos elaborados com base naqueles instrumentos de coleta de dados.

A estatística descritiva também teve expressão significativa nos artigos $(16,89 \%)$, empregada exclusivamente nos artigos classificados como quantitativos ou quali-quanti. Esta técnica apresenta a descrição sumária de dados quantitativos nos artigos. A categorização, que as vezes se confundi com análise de conteúdo, foi indicada em 14,9\% dos artigos, identificada a partir da separação do conteúdo analisado por meio de categorias, as quais eram previamente identificadas e estruturavam a apresentação dos resultados.

Outra técnica mencionada, como a análise do discurso, apareceu de forma marginal, em um número pequeno de trabalhos $(1,32 \%)$. Entretanto, trata-se de uma técnica com grande potencial analítico, que poderia ser mais empregada nos trabalhos qualitativos. O propósito da técnica de explorar as condições de produção dos discursos e não apenas os fragmentos explícitos nos discursos pode ser um caminho importante para se desvelar as relações sociais de poder e conflito inerentes à gestão universitárias, as quais são sempre mediadas por discursos.

Esses dados nos mostram ainda que a grande opção pela adoção de técnicas de cunho mais objetivista, de análises mais categóricas dos dados, em detrimento daquelas técnicas que exploram mais a subjetividade, pode estar sendo uma tendência da área. Porém, indicam, nesse mesmo caminho, outras possibilidades a serem exploradas nos artigos.

\section{CONSIDERAÇÕES FINAIS}

As análises do perfil metodológico dos trabalhos apresentados nos colóquios permitiram perceber certa evolução no uso dos métodos de pesquisa, técnicas de análise de dados e instrumentos de coleta, porém, com a ressalva de que a variedade ainda é reduzida. $\mathrm{O}$ perfil metodológico é caracterizado principalmente pelos métodos convencionais utilizados, encontrando-se muito pouco sobre novo métodos de pesquisa e inovações na execução dos trabalhos.

Em termos de métodos de pesquisa, os mais utilizados são o estudo de caso e a survey. Porém, a maioria dos artigos não relatou a utilização de um método, se restringindo a elencar os instrumentos de coleta de dados. Em relação a estes instrumentos, os mais comuns foram a pesquisa bibliográfica e a documental, principalmente devido ao grande número de artigos teórico, que representaram $47 \%$ do total de trabalhos analisados. Mas o questionário, a 
observação e a entrevista também foram instrumentos de coleta de dados muito utilizado. $\mathrm{Na}$ análise dos dados a utilização de análise de conteúdo e da estatística descritiva predominou. Em geral, a grande maioria dos trabalhos foi de abordagem qualitativa.

Pode-se coniderar, assim, que os resultados são expressivos em termos da indicação do perfil metodológico. Traçar tal perfil permite fazer considerações para além daquilo que é a realidade atual, indicando possibilidades para o desenvolvimento de futuros trabalhos e para a diversicação metodológica na tentativa de consolidar novos caminhos de pesquisa.

Sobre os métodos, dois daqueles que apareceram em pouquíssimos trabalhos, a pesquisa-ação e a etnografia, poderiam ser mais explorados, pois trariam visões complementares àquelas dos outros métodos, incluindo elementos simbólicos que dão sentido à gestão universitária enquanto prática social e dando voz aos gestores e funcionários enquanto protagonistas da gestão. Outros métodos poderiam ser sugeridos, alguns dos quais estão ganhando bastante amplitude na utilização de pesquisas em ciências humanas e sociais. Por exemplo, a grounded theory. Trata-se de um método científico qualitativo que utiliza um conjunto de procedimentos sistemáticos de coleta e análise dos dados para gerar, elaborar e validar teorias substantivas sobre fenômenos sociais, não partindo de um problema definido e de um teoria previamente delineada, mas deixando que o fenômeno se revele e que a teoria se desenvolva coerentemente com a visão dos sujeitos: a teoria, neste caso, deve emergir dos dados (STRAUSS e CORBIN, 1998).

Outro método são os mapas cognitivos, que Vergara (2005) define como representações dinâmicas ou modelos mentais elaborados por um indivíduo e relacionados a um objeto ou contexto particular. Que poderia ser utilizado para verificar como os gestores entendem as ligações entre diversos eventos e fatos que definem os processo de gestão universitária, permitindo representar esquematicamente relações de causalidade, influências e a dinâmica do processo de gestão com base nas percepções de seus gestores. Isso permite revelar as estruturas cognitivas que guiam as ações dos tomadores de decisão.

Mais um método sugerido, que atualmente tem se revelado de grande potencial com o grande avanço das redes sociais digitais, é a netnografia. Trata-se da derivação de um método tradicional como a etnografia, abrindo as portas para estudos de outros tribos e culturas, como as comunidades virtuais e a cibercultura (VERGARA, 2005). Assim como a etnografia, a netnografia demanda a imersão do pesquisador no ambiente pesquisa, com intensa observação das comunidades virtuais, registrando os participantes e suas intervenções na interação virtual. 
Observar as comunidades virtuais das universidades, seja nas páginas das próprias instituições ou em redes sociais, pode possibilitar entender como esta dinâmica virtual é incorporado no cotidiano da gestão e contribui com as estratégias organizacionais.

Estes foram apenas alguns dos vários métodos disponíveis para o desenvolvimento de pesquisas científicas que poderiam ser adotados em pesquisas na área de gestão universitária. A questão que fica como desafio é elevar o rigor metodológico dos trabalhos acadêmicos e diversificar o portifólio de métodos e técnicas utilizados, buscando novas visões sobre um mesmo objeto.

Como este trabalho teve o objetivo de identificar e apresentar o perfil metodológico dos artigos apresentados no colóquio de gestão universitária, não foi possível aprofundar numa análise da forma como os métodos estão sendo empregados ou analisar a relação do perfil metodológico com o posicionamento epstemológico dos autores. Isso extrapolava os objetivos deste trabalho, mas são questões relevantes para se compreender a constituição desse campo de conhecimento. Como um recorte arbitrário, as opções acerca dos métodos, técnicas e instrumentos metodológicos se restringiram àqueles citados nos artigos e de conhecimento dos autores deste trabalho, portanto, além das sugestões aqui mencionadas existe uma infinidade de possibilidades para se ampliar as opções futuras.

É preciso considerar também que não foi dada atenção aos problemas de pesquisa que motivaram e orientaram a produção científica analisada. Decorre disso que não basta descrever os métodos utilizados nos artigos se não se sabe se eles são os mais adequados para os problemas de pesquisa propostos. Será necessário para novas investigações a este respeito ampliar a extensão do material analisado para compreender estas particularidades. Mas espera-se que mesmo diante de tais limitações, este artigo possa ao menos despertar o interesse de alguns pesquisadores sobre novos métodos e sobre o rigor cinetífico de suas pesquisas. Ao longo deste trabalho foram apresentadas várias e importantes referências bibliográficas sobre metodologia científica, as quais poderão ser material de consulta para futuros trabalhos.

\section{REFERÊNCIAS BIBLIOGRÁFICAS}

ALYRIO, R. D. Metodologia Científica. PPGEN: UFRRJ, 2008.

BALDRIDGE, J. V. e DEAL, T. The dynamics of organizational change in educations.

California: McCutchan Publishing Corporation, 1983. 
BARDIN, L. Análise de conteúdo. Lisboa: Edições Setenta, 2011.

BRASIL. Lei N 9.394/96, de 20 de dezembro de 1996. Lei de Diretrizes e Bases da Educação Nacional. Estabelece as diretrizes e bases da educação nacional. Diário Oficial da União, Brasília, DF, 23 dez. 1996.

BRYNER, G. C. Organizações públicas e políticas públicas: In: B. G. Peters and J. Pierre (orgs). Administração Pública - coletânea, São Paulo, UNESP, 2010. pgs. 315-333.

CHAUI, M. S. A Universidade Pública sobre nova perspectiva. Rev. Bras. Educ. n.24 Rio de Janeiro. Set./Dez. 2003.

CHIZZOTTI, A. Pesquisa qualitativa em ciências humanas e sociais. Petrópolis: Vozes, 2006

CRESWELL, J. W. Research design: Qualitative, quantitative, and mixed methods.

Thousand Oaks: Sage, 2009.

FAVA-DE-MORAES, F. Universidade, Inovação e Impacto Sócio-Econômico. São Paulo em Perspectiva, São Paulo, v. 14, n. 3, p. 8-11, 2000.

FREITAS, H.; OLIVEIRA, M.; SACCOL, A. Z.; MOSCAROLA, J. O método de pesquisa survey. RAUSP - Revista de Administração, São Paulo, v. 35, n. 3, p. 105-112, 2000.

GIL, A. C. Métodos e técnicas de pesquisa social. São Paulo: Atlas, 1999.

GODOI, C. K.; BANDEIRA-DE-MELO, R.; SILVA, A. B. Pesquisa qualitativa em estudos organizacionais: Paradigmas, estratégias e métodos. São Paulo: Saraiva, 2006

GRACIANO, Mariângela; HADDAD, Sérgio. Educação: Direito Universal ou Mercado em Expansão?. Revista São Paulo em Perspectiva, Mar. 2004.

HUFF, A. S. Designing research for publication. Thousand Oaks: Sage Publications, 2008.

INEP. Censo da Educação Superior 2010. Brasília. 2011.

INPEAU. Instituto de Pesquisas e Estudos em Administração Universitária: Objetivos. Florianópolis. 2011. Disponível em $<$ http://www.inpeau.ufsc.br/wp/?page_id=8>. Acesso em: 12 de Fevereiro de 2011.

Gestão Universitária na América do Sul: I Colóquio Internacional. Florianópolis, 2012a. Disponível em: <http://www.inpeau.ufsc.br/coloquio01/index.htm>. Acesso em: $10 \mathrm{de}$ Dezembro de 2012.

INPEAU - Instituto de Pesquisas e Estudos em Administração Universitária. Florianópolis, 2012b. Dosponível em: < http://portal.inpeau.ufsc.br/inpeau>. Acesso em: 11 de Dezembro de 2012. 
II Coloquio Internacional Gestión Universitaria en América del Sur. Mar del Plata, 2012c. Disponível em: <http://www.inpeau.ufsc.br/coloquio02/index.htm>. Acesso em 11 de Dezembro de 2012.

III Coloquio Internacional sobre Gestión Universitaria en América del Sur: La Universidad Sudamericana Frente a la Crisis, la Integración Regional Y el Futuro. Buenos Aires, 2012d. Disponível em: $<$ http://www.inpeau.ufsc.br/coloquio03/default.htm $>$. Acesso em 11 de Dezembro de 2012.

INPEAU - Instituto de Pesquisas e Estudos em Administração Universitária: Colóquios. Florianópolis, 2012e. Disponível em: $<$ http://portal.inpeau.ufsc.br/coloquios/>. Acesso em: 11 de Dezembro de 2012.

LAKATOS, E. M.; MARCONI, M. A. Metodologia científica. São Paulo: Atlas, 1991

LAKATOS, E. M.; MARCONI, M. A. Técnicas de pesquisa: planejamento e execução de pesquisas, amostragens e técnicas de pesquisa, elaboração, análise e interpretação de dados. São Paulo: Atlas, 1986.

LOBO, L. R., SILVA FILHO. Gestão universitária e seus desafios. Revista Trevisan (Idéias). n. 11. São Paulo. 1998.

LOUREIRO, Maria Amélia Salgado. História das universidades. São Paulo: Estrela Alfa Editora, 1986.

LYONS, P.; DOUECK, H. J. The dissertation: from beginning to end. Oxford: Oxford University Press, 2010.

MALHOTRA, N. Pesquisa de Marketing: uma orientação aplicada. Trad. Nivaldo Montigelli Jr. E Alfredo Alves de Farias. $3^{\circ}$ ed. Porto Alegre: Bookman, 2001.

MANN, P.S. Introductory Statistics, 2nd Edition, John Wiley. New York. 1995

STRAUSS, A.; CORBIN, J.. Basics of qualitative research: grounded theory procedures and techniques. Newbury Park, CA: Sage Publications, 1998.

VERGARA, S. C. Métodos de pesquisa em Administração. São Paulo: Atlas, 2005.

WANDERLEY, Luiz Eduardo W. O que é universidade? São Paulo: Editora Brasiliense. 9. ed. - Coleção Primeiros Passos, 1988.

YIN, Robert. Estudo de caso: planejamento e métodos. 3. ed. Porto Alegre: Bookman, 2005. 